\begin{tabular}{|l|l|l}
\hline & $\begin{array}{l}\text { Proceedings of the } \\
\text { Informing Science }+\end{array}$ & $\begin{array}{l}\text { An Official Publication } \\
\text { of the Informing Science Institute } \\
\text { InformingScience.org }\end{array}$ \\
\hline
\end{tabular}

\title{
CyberseCURITY, IT-AIDED EDUCATION, AND TELES: NEXUS, VISTAS \& REALITIES
}

\author{
Emmanuel C. Ogu* \\ Department of Computer Science, \\ School of Computing and Engineer- \\ ing Sciences, Babcock University, \\ Ilishan-Remo, Ogun State, Nigeria. \\ Chiemela Ogu \\ EMINDA Konsults, Yaba, Lagos, \\ Nigeria. \\ * Corresponding author
}

ecoxd1@yahoo.com

chiemelaogu@gmail.com

\begin{abstract}
Background The current decade has witnessed rising spates of threats and attacks that have threatened the safety and security of cyberspace, thereby giving rise to contemporary discourses pertaining the realities that these ominous trends portend for technology innovation and digitalisation, in the emerging global digital society. In the process, the technological capabilities that have been used to effectively harness the efficiency that this virtual space provides for contemporary education and learning have been defamed.

Aim/Purpose This exploratory research interrogates the possible relationships between the contemporary concerns of global cyber security, and the realities and prospects of IAE and TeLEs, while elucidating the crucial factors that impose on such relationship(s).

Methodology This research adopts the qualitative research methodology with an exploratory approach to interrogate the various contemporary concerns of global cybersecurity as contained in existing literature, especially as it affects the proliferation and adoption of IT-aided education and Technology-enhanced Learning Environments (TeLEs); based on a systematic correlational analysis of key interposing concepts.

Contribution The research presents an overview of the current status and prospects of development of IAE and TeLEs, as well as the nature of the realities associated with contemporary concerns of global cybersecurity; then also discussing how these cybersecurity concerns impact on the wider adoption and implementation of IAE and TeLEs.
\end{abstract}

Accepting Editor: Eli Cohen | Received: October 21, 2018 | Revised: November 18, 2018 |

Accepted: November 24, 2018.

Cite as: Ogu, E. C., \& Ogu, C. (2019). Cybersecurity, IT-aided education, and TeLEs: Nexus, vistas \& realities.

Proceedings of the Informing Science and Information Technology Education Conference, Jerusalem, Israel, pp, 3-19. Santa Rosa, CA: Informing Science Institute. https://doi.org/10.28945/4153

(CC BY-NC 4.0) This article is licensed to you under a Creative Commons Attribution-NonCommercial 4.0 International License. When you copy and redistribute this paper in full or in part, you need to provide proper attribution to it to ensure that others can later locate this work (and to ensure that others do not accuse you of plagiarism). You may (and we encourage you to) adapt, remix, transform, and build upon the material for any non-commercial purposes. This license does not permit you to use this material for commercial purposes. 
Findings The contemporary concerns of global cybersecurity that were discovered to impact on IAE and TeLEs include: Academic Dishonesty, Misconduct and Malpractice, Fake News, Steganography \& Malware, and Cyberbullying. The interrogation of these concerns lead to an elucidation of the associated factors and interactions that have hampered the wider development and adoption of IAE and TeLEs for education, teaching and learning in the 21st century. These are properly positioned in reality by drawing on evidences and deductions from existing researches, and supported with real-life case studies to explain the implications of the portended realities for the emerging global information society.

Recommendations The EMINDA cybersecurity framework for TeLEs is presented as a better way for Practitioners $\&$ Researchers forward for lifting the future of IAE and TeLEs out of the quagmire it has been plunged into by the contemporary concerns of global cybersecurity. This framework synthesizes aspects of existing security strategies that have been deployed successfully to insure cybersecurity for various other digital and technological application domains.

Impact on Society The revolutionary impact of technology and digitization of teaching and learning in the modern era has come to stay, with exciting prospects for the future of the emerging global information society. At the same time, the realities of global cybersecurity have equally come to stay with rather daunting consequences and debilitating future prospects. This research presents a way forward even in light of these debilitating concomitant realities.

Future Research Future research would focus on implementing the EMINDA cybersecurity framework in a prototype TeLE, and evaluating the effectiveness and efficiency of the framework in guaranteeing cybersecurity for a test case sample of participants that would feature in the evaluation.

Keywords TeLEs, IT-aided education, cybersecurity, technology \& education, information technology, technology \& learning, pedagogy, information society

\section{INTRODUCTION}

The pervading influence and impact of information and communication technologies across all areas of human endeavour has, indeed, come to stay. Indeed, various forms of computing devices \& systems, networks and the Internet have remarkably transformed traditional modes of operations and activities in every area of human endeavour. This has brought with it the capacity to carry out traditional activities with such efficiency and productivity that before this time was barely possible. Across the areas of healthcare and medicine; education and pedagogy; urban and regional planning; agriculture and food production; genetics and biology; transportation and navigation; banking and finance; government and politics; economics and trade; civic and public administration; law and jurisprudence; nuclear and critical / hazardous ecology monitoring, safety and security; research and development; innovation and intervention, amongst many others; information and communication technologies have garnered controlling stakes in ways that remain difficult to contest. This has created an evolving digital society that has survived through many challenges - where digitalization has become the rule of engagement.

Education and Pedagogy is one such discipline within which the extensive impact and influence of information technology is difficult to gainsay. From the popularization of various forms of Computer-aided Instruction (CAI) / IT-aided education (IAE) media, such as learning enhancement through the use of multimedia, to the growing adoption and applications of E-learning and the increasing acceptance and participation in technology-enhanced learning environments (TeLEs), information 
and communication technologies have greatly revolutionized the traditional pedagogical landscape and boosted capability within the domain. Through the ubiquity that information technology (IT) provides, learning can now take place without restrictions to location / geography. The flexibility that comes with IT has also made it possible for teaching and learning to take place at the convenience of both the teacher and learner. The efficiency of IT further made successful the growing popularity of digitalised professional assessments and examinations; just as curricular content for STEM courses that were traditionally perceived to be 'difficult' to teach and learn, even within face-to-face classroom settings, have been successfully delivered to remote learners, powered by the effectiveness of IT.

In the multi-dimensional nature of the modern information and communication technology landscape, where various technological media (text, video, or voice) are adopted for propagating and transmitting information across various participant configurations (one-to-many, many-to-one, focus groups, and larger participant communities), and for various purposes (professional, social, academic, collaboration, or knowledge dissemination), contemporary concerns have emerged with regards to the impact and implications of the modern realities of global cybersecurity on the derived and portended benefits of information and communication technologies across various application domains. Within the context of education and learning, some of the problems and challenges that have been popularly associated with traditional teaching and learning environments have been aggravated by the growing popularization of IT-aided education and Technology-enhanced Learning Environments (Casey, Casey, \& Griffin, 2018).

In lay terms, IT-aided education and Technology-enhanced Learning Environments generally belong in a field known as "e-Learning" - a broad discipline / specialisation that is focused on the methods, techniques and technologies that facilitate the digitalisation of the education, teaching and learning process. "IT-aided education" (IAE), a term that has been used interchangeably with "computerassisted education" and "computer-aided learning", essentially refers to the use of computers and modern information technologies to facilitate the transmission of knowledge to individuals (learners), typically by adopting various media for digital propagation. However, "Technology-enhanced Learning Environments" (TeLEs), also known as "virtual learning environments" further expands on the concept of IT-aided education to incorporate the idea of not just learning through the aid of technology, but also learning within (the presence of) technology particularly in the context of technology-enhanced classrooms and learning environments.

Incidentally, a lot of global cybersecurity concerns have trailed the adoption and implementation of IAE and TeLEs in recent years. Some of the more popular of these have been related to: academic integrity as highlighted by Casey, Casey, and Griffin (2018), Nicolaides (2018), Blau and Eshet-Alkalai (2017), and Jones (2016) amongst others; obscenity as highlighted by Castellanos, Manson, and Zhou (2017), and Sarac (2014) amongst others; as well as cyberbullying as highlighted by Torres and Vivas (2016). These are but to mention a few. These concerns have now begun to transform into polemical debates that have sometimes ended up polarised. It has therefore become necessary to delve into these issues in a bid to excavate and elucidate some of the underlying and surrounding realities and their implications for the advancement and development of IAE and TeLEs.

Hence, this research presents an exploration and analysis of these (aforementioned) and associated contemporary concerns of global cybersecurity that have impacted on the wider adoption and development of IAE and TeLEs, as well as the portended realities for the future of information technology in education and learning. By adopting the qualitative research methodology with an exploratory approach, this research interrogates the various contemporary concerns of global cybersecurity as contained in existing literature, especially as it affects the proliferation and adoption of IT-aided education and Technology-enhanced Learning Environments (TeLEs), based on a systematic correlational analysis of key interposing concepts. In light of this, the rest of this research proceeds as follows. 
The following section presents an overview of the key concepts that bother on the research discourse, viz., IAE, TeLEs, and the contemporary concerns of global cyber security. The goal in this section is to present a systematic discourse that succinctly elucidates on the impact of contemporary cybersecurity concerns on the current status of IAE and TeLEs.

Next, the implications of the emergent realities for the future of information technology in teaching and learning, as well as the future of effective and productive IAEs and TeLEs, are presented by combining qualitative research evidences and anecdotal case study reports.

Finally, the EMINDA Framework is proposed that presents a better way forward in light of the concomitant realities uncovered by the research discourse.

\section{CONCEPTUAL OVERVIEW}

As highlighted, this section presents an overview of the key concepts that are contingent upon this research.

Figure 1 illustrates the approach of the conceptual discourse that would be featured in this section of the research.

A brief overview of the development, contemporary disposition, derived benefits, and prospects of IT-aided Education (IAE) and Technology-enhanced Learning Environments (TeLEs) is presented, and then evidences from media reports and academic sources are drawn to elucidate on how the contemporary concerns of global cybersecurity have impacted on the wider adoption and implementation of IAE and TeLEs for education and learning in the $21^{\text {st }}$ century.

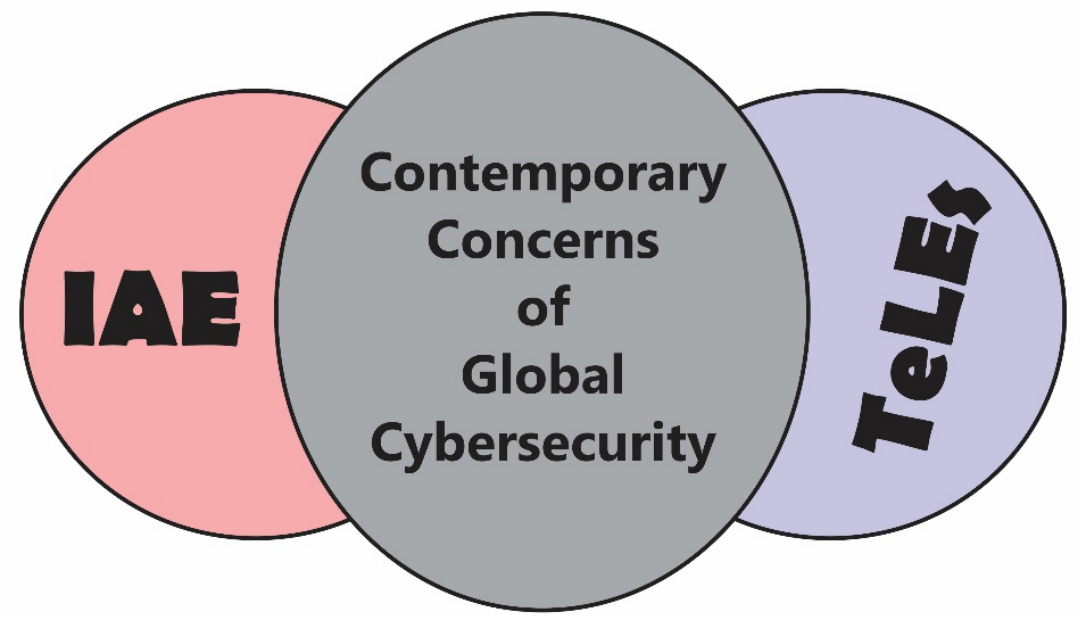

Figure 1: Framework for Research Conceptual Discourse

As illustrated by the interactions in Figure 1, if the contemporary concerns of global cybersecurity for IT-aided Education and Technology-enhanced Learning Environments are relegated and not keenly and carefully considered, the growing effects and impacts of these contemporary concerns could potentially strangle the future of IAE and TeLEs. It is in light of this that this research systematically interrogates the status and the interactions between the key interposing concepts and cooccurring factors that bother on this portended reality.

\section{IT-AIDED EDUCATION (IAE)}

IT-aided Education - learning through the aid of various information technology media (such as text and short messages, video, voice, graphical illustrations, animations, digital scenarios \& case representations, and other forms of digital teaching aids / media (Cingi, 2013), as well as the various software, 
systems and devices that enable manipulation and access to information propagated by such media) has extensively enhanced the traditional learning processes and with greater quality, efficiency and retention effectiveness.

In a research conducted by Uzunboylu and Tugun (2016), it was deduced that mobile tablet devices helped to enhance the quality and reliability of education and training received by students. Similarly, computer-aided instructional materials were proven an effective tool for teaching individuals to conduct assessments for deducing stimulus preferences in another research by Arnal-Wishnowski, Yu, Pear, Chand, and Saltel (2018). This is in tandem with the results of a separate research by Scamell and Hanley (2017), which experimented web-based interactive storytelling as an effective, low-cost and globally applicable computer-aided instructional tool to help students of midwifery better understand compassion and empathy.

In the same vein, concept cartoons were part of computer-aided multimedia instructional materials used in educating students on the ecological, astronomic and economical results of light pollution; the results showed improved understanding and awareness of the causes and implications of light pollution by the students, helping them to develop preventive solutions for light pollution (Aydin, 2015). However, Babiker and Elmagzoub (2015) argued that for multimedia teaching aids to be able to achieve the desired impact on the learning process, such media have to be designed by the teachers themselves using available multimedia authoring tools, and taking into cognisance the curricular structure, existing hardware and software infrastructural capabilities, and the need for effective evaluation.

Ozofor (2015) in an empirical study also discovered that computer assisted instruction and teaching methods used in teaching statistics and probability helped improve learners' performance and stimulate interest, while also enabling long-term knowledge retention. Facets of this discovery have been separately corroborated by Mo, et al. (2015), Chen and Wu (2015), and Leow and Neo (2014), amongst others. However, Kwon, et al. (2015) veered away from these positions in concluding that "technology-assisted training did not [positively] affect ... students' waxing performance or selfevaluation skills" in a dental anatomy waxing class, which was traceable to a non-strategic approach to curricular integration.

Yet evidently, there exists a majority consensus of existing research and literature that lends credence to the assertion that the current status and development of IAE and various forms of computerassisted instruction / learning have transformed the traditional methods of teaching and learning, and has indisputably brought greater productivity, efficiency and effectiveness into the modern learning process.

\section{TECHNOLOGY-ENHANCED LEARNING ENVIRONMENTS (TELES)}

TeLEs - the paradigm of learning amid technology - has greatly transformed the traditional methods and practices of teaching and learning, and has popularised the idea of virtual learning environments (LEs). Herein, various technological tools and capabilities (such as 3D Learning, Simulations, Virtual / Augumented Reality, and Tele-classrooms, amongst others) have come to bear in facilitating and enhancing the ways and manner by which learning is delivered and managed (Doumanis, Economou, Sim, \& Porter, 2018). Schott and Marshall, (2018) discovered that such virtual TeLEs are able to provide a learning experience that is holistically analogous to that obtainable from traditional learning environments in the physical space, which often suffer from barriers of high costs (RománIbáñez, Pujol-López, Mora-Mora, Pertegal-Felices, \& Jimeno-Morenilla, 2018), feasibility (De León, 2018), and ethicality. This is a position that is corroborated by Mortara and Catalano (2018)

Furthermore, TeLEs enable: access to knowledge experts that are not physically present; acquisition of experiences that rely on resources that are either scarce or not widely accessible; and acquisition of learning experiences that may otherwise have been physically impossible (Greenwald, et al., 2017). In the same vein, de Jager (2017) discovered a positive correlation between technology-enhanced 
learning and comprehension capabilities across learning barriers, active involvement in the learning process (also, [Ferdig, Gandolfi, \& Immel, 2018]), and improved attention span.

Bronack, et al. (2008), in keeping with the socio-constructivist philosophy of traditional learning in the physical space, proposed ten principles for guiding the development and management of virtual TeLEs, in what has become widely known as the "presence pedagogy" (P2) model. The presence pedagogy model suggests that virtual TeLEs should incorporate capabilities for:

1. questions to be asked and misconceptions corrected;

2. awakening the foundational knowledge, competences and experiences of the learner to establish a necessary contingence between traditional theory-based pedagogical knowledge domain and the real world;

3. obscuring the perceptions of a knowledge and expertise hierarchy that is characteristic of traditional learning models, so that peer-based learning and knowledge sharing can take place, even serendipitously;

4. engendering and fostering the clustering of cross-disciplinary learning communities through mediated peer interactions and collaboration;

5. facilitating distributed learning through a diversified pool of participants, supporting technologies, active cognitive engagements;

6. "continuous, collaborative and active learning" powered by tools and resources for sharing content;

7. establishing an inclusive learning context with clearly delineated teaching \& learning goals for participants to act upon;

8. encouraging and motivating students to pursue, discover, share and apply knowledge in a way that makes sense to them; while also

9. encouraging them to apply such knowledge to practice in such a manner that allows them to ponder upon the meaning, context and validity of the processes and results; and

10. actualising and disseminating results through technology-enabled media

The P2 model has since formed a significant part of the bedrock and blueprint for a number of modern virtual TeLEs, such as that proposed and / or experimented in recent researches by: RománIbáñez, Pujol-López, Mora-Mora, Pertegal-Felices, and Jimeno-Morenilla (2018); Liu, Liu, and Ren (2018); Doumanis, Economou, Sim, and Porter (2018); Gautam, Williams, Terry, Robinson, and Newbill (2018); Thomas and Schneider (2018); Becerra, et al. (2017); and Wang, Petrina, and Feng (2017), to mention a few. All these researches have extensively incorporated the P2 model in the development of state-of-the-art virtual learning environments across various jurisdictions. However, Bower, Lee, and Dalgarno (2017), identified limited co-interaction (sometimes due to technological limitations), comprehension and reaction disparities due to lack of effective communication, and technological unreliabilities as some of the possible challenges that participants in TeLEs could experience.

These notwithstanding, there exists a wide consensus corresponding to a vast majority of existing research that confirms rather credibly and empirically that TeLEs have revolutionised education and learning in modern times. Distant Learning, powered by online TeLEs, has become a viable means for educational institutions to scale globally in exponential proportions, with respect to the diversification and coverage of their knowledge dissemination capabilities. The attending benefits have typically come with cost effectiveness, management efficiency, and capabilities for learning flexibility, learner inclusiveness, strategic peer collaboration, and knowledge dispersion. The integration of cloud computing into legacy TeLE frameworks is also leading to the popularisation of a phenomenon that would soon be known as "learning as a service" or "education as a service", where curriculumbased educational content is made available on-demand, delivered on a subscription basis, and accessible ubiquitously, in an environment that is both trans-institutional and jurisdiction-independent. The likes of Coursera, Udemy, EdX, and other cloud-based TeLE platforms have championed and 
continued to push the frontiers of this new phenomenon that is expected to experience rapid development, and witness more extensive usage and participation in the near future.

In chronicling the progressive journey from the integration of IAE into traditional teaching and learning methods to the blooming of full scale TeLEs within one national context, Ng'ambi, Brown, Bozalek, Gachago, and Wood (2016) discuss how South Africa began by integrating technology and computer aided instruction into traditional learning practices, taking into cognisance the impact and implications of the digital divide. Following this, institutions began to build their ICT infrastructural capabilities, supported by robust policy development and research towards an information democracy, in a bid to understand how teaching and learning can be enhanced using technology. Institutions then began to integrate ICT into their strategic development agenda, even as the discourse on the digital divide began to witness an epistemological drift so that research focus was aimed at pedagogical development; and today, mobile learning and education through social media have become the new phenomenon in education in South Africa.

This position is corroborated by Trelease (2016), which chronicles the progressive journey of how IAE and TeLEs have transformed traditional methods of education in the anatomical sciences. The research elucidates the progression from the era of "printed textbooks, chalkboard- and photographic projection-based classroom lectures, and cadaver dissection laboratories" to programmable digital multimedia for descriptive anatomical imaging, to full scale medical imaging capabilities for computed tomography, magnetic resonance imaging, and ultrasound, and then on to recent inclusions of digital video and structural simulations. Hence, it simply cannot be gainsaid that IAE and TeLEs have, indeed, revolutionised the $21^{\text {st }}$ century education story.

The proliferation of microcomputers, mobile technological devices and mobile communication networks have arguably been the wings that have borne the success of IAE and TeLEs, and made it the fulcrum of $21^{\text {st }}$ century education. As chipset and microprocessor technologies continue to develop and advance, there is expected to be wider applications of these technologies for mobile computing as well as micro-computing. Then when combined with the prospects of the Long Term Evolution / $4 \mathrm{G}$ networks for high-speed and high-quality communication, these existing benefits of IAE and TeLEs are expected to grow exponentially, as more IAE media and virtual learning models would emerge for the purpose of contemporary teaching and learning.

\section{CONTEMPORARY CONCERNS OF GLOBAL CYBERSECURITY IMPACTING ON IAE AND TELES}

Contemporary concerns of global cybersecurity have arguably had a prevailing negative impact on the wide adoption, implementation and subscription to IAE and TeLEs. This is due to the fact that the challenges and vices that teachers, education administrators and policy makers have had to deal with in traditional learning environments have been exacerbated by the proliferation and popularisation of IAE and TeLEs. While the contemporary discourse surrounding the realities that cybersecurity portends for IAE and TeLEs yet remains quite polarised, there exists a preponderance of case studies within the scope of existing knowledge that lends credence to both sides of the debate.

The key arguments pertaining the benefits and advantages of IAE and TeLEs for modern education, teaching and learning have already been highlighted in the foregoing sections of this research. However, much research evidence limpidly suggest that the realities of contemporary cybersecurity are able to potentially obscure some of the benefits and advantages that IAE and TeLEs avail for modern teaching and learning.

Hence, the focus of this sub-section is to succinctly present some of the more popular concerns of global cybersecurity that have negatively impacted on the wider adoption, implementation and subscription to IAE and TeLEs, as well as the contemporary discourses surrounding these concerns; while throwing in a few case studies in a bid to better position the status and context of emerging realities. 
Academic dishonesty, misconduct and malpractice

The concept of academic dishonesty, misconduct and malpractice in learning environments is indeed not new. However, contemporary concerns regarding academic dishonesty, misconduct and malpractice within TeLEs and IAE generally involve issues relating to the integrity of assessment procedures, plagiarism, malicious collusion, falsification \& fabrication, impersonation, amongst others. The recent global polemics regarding data privacy and integrity further validates the relevance of these concerns.

In an empirical research carried out by Blau and Eshet-Alkalai (2017) to understand the extent to which technology might be aiding and abating students in academic misconduct, it was discovered based on a calculated Ethical Dissonance Index (EDI) - the difference between the pervasiveness and the perceived legitimacy of various types of academic dishonesty - that students engage in acts of academic dishonesty across digital and non-digital settings despite the widely accepted perception that it is non-ethical. In the scenario-based research involving 127 grade 7 students, which explored the "tension in academic dishonesty between students' dishonest behaviour and their ethical values and beliefs", different scenarios of academic dishonesty (cheating, plagiarism, fabrication, and facilitation) across digital and non-digital settings were administered to participants. It was discovered that plagiarism "is the most common type of AD [academic dishonesty], perceived as the most legitimate, and characterized by the greatest EDI" within digital settings. Conversely, however, Tsai (2016) discovered that there was statistically no difference between students' behaviours and perceived participation in acts of academic misconduct in a supervised and unsupervised online learning environment. This finding was also similar to that discovered by Black, Greaser, and Dawson (2008), which uncovered that contrary to popular suppositions, the notions that apply to academic dishonesty in face-to-face learning environments do not necessarily bother on online learning environments. Cronan, McHaney, Douglas, and Mullins (2017) went on to implement a technological intervention that helps to enhance the knowledge and attitudes of participant student populations towards academic integrity in learning environments.

In essence therefore, despite rife concerns about the possibility that IAE and TeLEs may indeed be contributing to higher levels of academic dishonesty in modern education, there is insufficient research and media evidence to validate these concerns. However, the absence of much tangible research evidence would also not be sufficient grounds to dismiss these concerns as baseless paranoia; especially when considered in light of the critical liability effects that widely available reports of such academic dishonesty could have on both the reputations of educational institutions, course instructors, and the perceived competence of the students in the job market.

In addition, the popularisation of various easy-to-use digital media editing tools and application software enables the ease of falsification of electronic academic documents and credentials on the go, and where digital document verification systems and policies are absent, the likelihood of such practices festering incognito also increases greatly.

\section{Fake news}

The proliferation of fake news in the contemporary mass media also impacts considerably on the adoption and proliferation of online virtual learning environments. The propagation of canards within TeLEs, especially when such environments are not instructor-monitored and moderated for disseminated content, could portend serious implications for civic reasoning, especially amongst school-age teenagers, adolescents and young adults in a virtual space where content can often not be clearly delineated as 'fake' or 'real'; McGrew, Ortega, Breakstone, and Wineburg (2017) argue. Alexander, Becker, Cummins, and Giesinger (2017) give voice to this concern, specifically with regards to how impossible it would be to expect learners to create reliable digital content when they are themselves unable to judge the reliability of digital content; with McGrew, Ortega, Breakstone, and Wineburg (2017) further adding that providing learners with guidelines or checklists for discerning content reliability actually makes them more vulnerable to fake news due to the inherent difficulties in being able to correctly judge digital content as being either 'fake' or 'real'. 


\section{Steganography $\&$ other malware}

The term "malware" is essentially a collocation of two separate English words: "MALicious" and "softWARE". In other words, a malware, without any loss of meaning or understanding, may fundamentally be defined as any software that is engineered or useful for malicious purposes / intent. Various types and classes of malwares exist today, such as viruses, worms, Trojans, spyware, adware, rogueware, ransomware, botnets, to mention a few. Each of these classes of malwares have specific behaviours and characteristics that distinguish them from their counterparts. For example, while worms are self-propagating, viruses are not, but rely on some form of "aid" to achieve propagation; also, adware are obtrusive and invasive, while spyware are not, but typically sit quietly in machines, and gathering sensitive information that could serve some malicious purposes.

In the early days of computing in the 1990s, the existing malware were only between 1000 and 2300 in number. However, today there exists about 1,000,000 different types and families of malware (Kumar, Kumar, \& Kumar, 2014), and the number of reported cyber incidents due to these malware has escalated over the years. Symantec (2017) even recently reported an increase in distinct malware variants from 275 million to 357 million between 2014 and 2016.

Steganography, an advanced and extended application of malware capabilities, is a technical term that refers to the embedding of malicious programs / information into picture, audio, and video files.

Steganography is a concern that has in recent times trailed the use of electronic teaching aids and the propagation of digital media; especially those that are transmitted within online TeLEs. The growing popularity of steganographic tools and applications, even within the domain of mobile communications, have indeed aggravated these concerns.

Much existing research evidences give voice to concerns associating Steganography with the modern rise of terrorism and the rising emigration of school-age teenagers from the West to join terrorist groups in the Middle East as recruits. Some of these research evidences are elucidated in-depth by: Burney (2018); Cullen (2017); Coglitore (2017); Eaton (2016); Storms (2016); and Bogdanoski, Risteski, and Bogdanoski (2015), amongst many others. Also, Rout and Mishra (2014) have further associated steganography with data theft and the propagation of (child) pornography.

While much of these concerns have been assuaged by modern advancements in steganalysis and its growing applications within the military for the purpose of national security; steganography yet provides a viable digital medium for propagating leaked assessment information / documentation, profanity, pornography, and occultic / terrorist ideologies amongst other nefarious vices within TeLEs, where advanced applications and skillset in steganalysis are often absent.

\section{Safety of the learning environment}

Another germane concern that has hindered the wide adoption of IAE and TeLEs, especially at the elementary to junior cadres of education, teaching and learning has been the concern of how to maintain a safe and conducive learning environment that is free from offensive / inappropriate content, such as those associated with racism, shaming, assault, brutality, and obscenity. One rather progressive and widely adopted solution to this challenge has been the incorporation of content filters that are able to keep out racist, obscene and immoral content from the learning community. However, as modern trends of popular culture have continued to constantly push the boundaries of what type(s) of content may be tagged as inappropriate and for what age category, the efficacy of content filters in universally addressing this concern has diminished considerably.

The rise in anti-Islamic movements due to the rising spates of global terrorism has resulted in increasing statistics of hate speeches being propagated around physical and virtual campuses and learning environments across many jurisdictions. This has often resulted in hate crimes, and has led to concerns about the safety of learning environments; because, as Castellanos, Manson, and Zhou (2017) argue, college campuses and learning environments (be they in the physical or virtual space) are indeed microcosms of the larger contemporary society; and it is very easy for such concerns to 
bring about realities that crisscross both spaces. Death threats, and the fluctuating trends of global racism, shaming and verbal assault have also further complemented these concerns.

\section{Cyberbullying}

Concerns have also been voiced regarding the carrying across of bullying from the contexts of traditional learning environments in physical schoolyards into online / virtual TeLEs, in a term that has been technically referred to as cyberbullying. TeLEs provide a viable frontier for cyberbullying and obscure the benefits of IAE. Cyberbullying can be understood to involve the (repeated) use of information technology devices and systems to aggressively threaten, harass, intimidate, induce stress / distress, cause harm / panic, or attempt to coerce other individuals to yield to certain actions / viewpoints that they are otherwise not inclined to. Acts of cyberbullying in this context could include: assaulting, defaming, terrorizing, blackmailing, shaming, privacy invasion, and unsolicited obscenity, especially in a repeated manner. Davis (2012) alludes to a particular case in which two female teenagers were arrested by Florida Police for cyberstalking a peer and using the information obtained to create a Facebook profile impersonating her, which was used in bullying her.

While much of the body of research, legislative and academic policy efforts have been focused on addressing the problem of cyberbullying at the K-12 elementary, and secondary education levels, the problem of cyberbullying has been discovered to be one that permeates all implementations of online / virtual learning environments enhanced by technology, and impacts on all categories of participants; regardless of educational level (Smith \& Yoon, 2012; Minor, Smith, \& Brashen, 2013). Torres and Vivas (2016), argue that the widening digital divide perpetuates a lack of understanding and consensus of what constitutes the right and wrong use of the Internet, and also makes it difficult to manage issues of cyberbullying across varying social contexts that are widely removed. This often results in a spiral convolution of myths, suppositions, opinions and perspectives that have no empirical foundations; and in some cases, incidents that often go unnoticed and thereby unreported.

The reality of bullying within virtual learning environments has been buttressed by much existing research efforts. Sarwar, Zulfiqar, Aziz, and Ejaz Chandia (2019) discovered that "social media serves as a dynamic tool to expedite the development of learning environments by encouraging cooperation and communication among students which reinforce their learning behaviour and performance", but also that cyberbullying is "a dampening factor in the positive relationship between collaborative learning and learner performance". Lowry, Zhang, Wang, and Siponen (2016) investigated the possible reason(s) for this discovery by seeking to understand why adults engage in cyberbullying on social media; they discovered that this is traceable to an increased usage of social media, and the perception of anonymity within the virtual cyberspace. Sapouna, Enz, Samaras, and Wolke, (2015) thus present a virtual role-playing intervention to stem spates of cyberbullying by arming children and adolescents in primary school with coping strategies when faced with cyberbullying.

Essentially, however, there does not seem to be any discovered dissonance of research evidence pertaining the dangers that cyberbullying portends for the growing adoption and implementation of IAE and TeLEs; and this, perhaps, reveals how germane the concern of cyberbullying is for online LEs.

\section{IMPLICATIONS \& REALITIES}

Incidentally, not much research attention has been paid to the concern of how social misconducts and vices - such as bullying, racism, academic misconduct / malpractice, obscenity, profanity, shaming, etc. - that administrators, instructors and teachers have consistently had to deal with in traditional learning environments, can be effectively confronted within the contexts of IAE and TeLEs. Especially in such a manner that is effective and does not truncate the intended benefits for the learners. With the recent extension of the concept of IAE and virtual TeLEs into the pervasive and ubiquitous domain of mobile information technologies (Olmos, Cavalcanti, Soler, Contero, \& Alcañiz, 2018), this concern assumes a more crucial nature with portended realities that could be daunting. 
Davis (2012) also discusses how issues of impersonation, identity-theft, cyberstalking, and cyberbullying have plunged many schools in the developed world into much legal distress and raised germane concerns about the safety and security of digital and non-digital learning environments; especially since some Western countries like Canada have saddled educational institutions with the responsibility of protecting students from such vices.

Learning environments are typically characterised by complex and co-imposing factors of context, learning content and participant diversification (Liu, Bhagat, Gao, Chang, \& Huang, 2017); as well as dynamic and co-dependent interactions that are also rather complex by nature (Cheney $\&$ Terry, 2018). This, perhaps, accounts for why the conclusions of various recent studies that have attempted to categorically answer the question of whether or not virtual TeLEs definitely contributes to the contemporary learning experience can be sometimes contradictory. Many sources have advocated the establishment of well-defined roles and norms within TeLEs and communities to help guide participation and resolve disputes. However, while this portends a promising solution frontier to some of the cyber security related concerns of IAE and TeLEs, the fluid and trans-jurisdictional nature of such learning spaces, which often comprises participants from diverse removed jurisdictions, brings in additional complexities associated with the digital divide and with the acceptance and enforcement of trans-jurisdictional technological / digital regulations. These complexities primarily relate to whether or not the actual jurisdictional digital contexts of all participants in the learning environment are able to deal with the realities associated with abiding by the defined norms and roles of the learning environment.

Sources, such as Lee-Post and Hapke (2017), have suggested that biometrics, surveillance systems and predictive analytics could help enhance electronic authentication of learning participants, and curb the spates of impersonation in virtual learning environments. They argue in line with the United States' Higher Education Opportunity Act of 2008 that institutions seeking to harness the efficiency of virtual LEs must have a way of: ensuring that only registered users have access to the LEs, tracking the learning progress of participant learners, and detecting $\&$ deterring acts of academic misconduct. Other sources also tend to agree that digitalization of student assessment records could help downturn the tides of plagiarism. But then, the question that yet begs for an answer remains: "how do we achieve a balanced cybersecurity framework for TeLEs that would be inclusive, pragmatic, feasible, and effective?"

\section{A BETTER WAY FORWARD}

Perhaps, a better way forward would begin with all users of IAE media and participants in TeLEs reckoning that virtual learning environments are autonomous and jurisdictionally-inclusive environments where policies would be made and enforced to safeguard activities, communal interests, and also preserve the focus and goals of the environment. Figure 2 presents the EMINDA framework that illustrates the operations and interactions that would feasibly take place in such a context.

Within this framework, "A" is any user that seeks to propagate IAE digital content within the LE, while "B" are participants within the LE that have pre-configured security policy profiles within the learning environment to align with their technological capabilities, sensibilities and sensitivities. These pre-configured cyber security policy profiles are securely stored and administered on a database server deployed within the LE. Every digital content sent by user " $\mathrm{A}$ " is first screened by a security scanner for possible steganographic content as well as other malware accompaniments. Next, the content is filtered and further classified for viewing and access by each participant(s) within the LE, based on the configured security policy profiles of such participant(s). By such means, TeLE participants would only view and access content that strictly aligns with their sensibilities and sensitivities as contained in custom and pre-configured security policy profile, or a decently configured default profile (possibly based on declared participant ages) in the event that such a participant has no security profile configuration stored on the database server. 


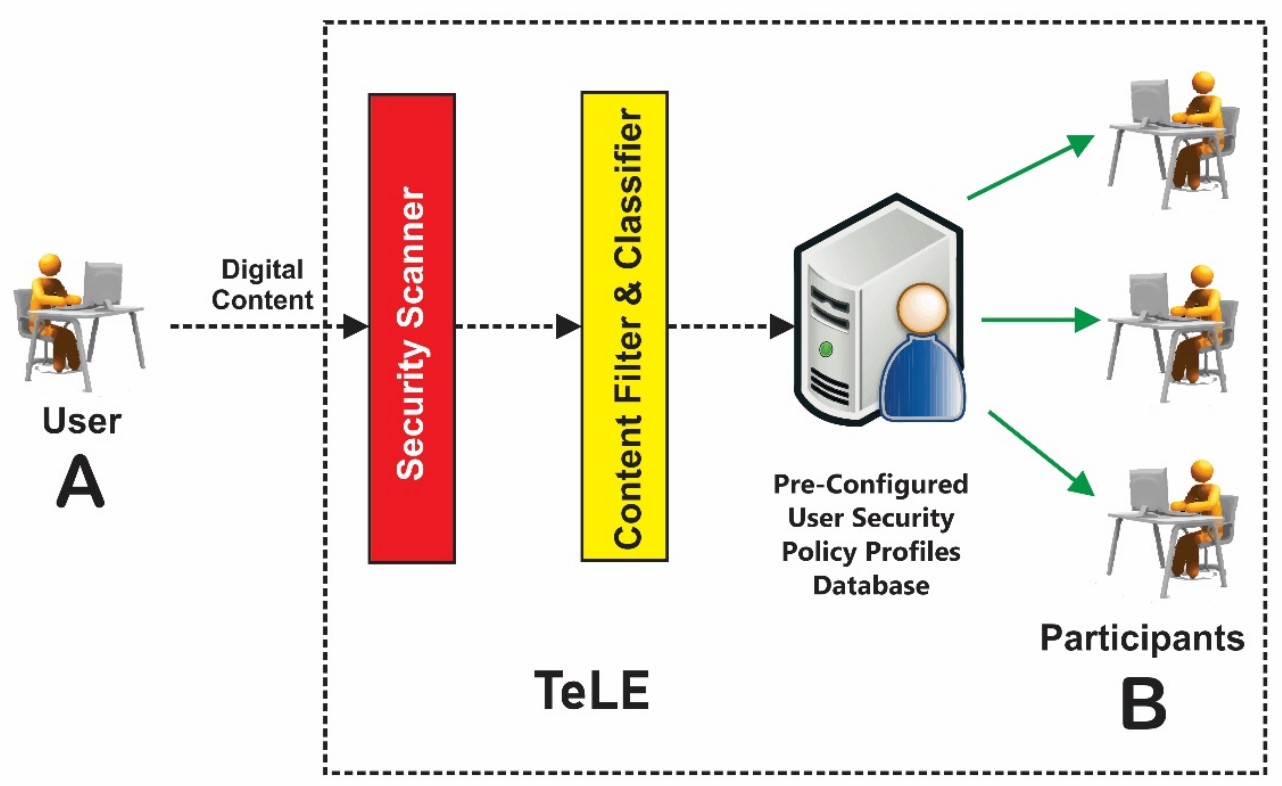

Figure 2: The EMINDA Cybersecurity Framework for TeLEs

Furthermore, within such a framework, it would become easy to implement and periodically review and adapt additional policies and protocols to ensure the verification of electronic academic documents and other digital media that are propagated within the LE, and notify appropriate authorities accordingly; while also integrating tools and software to verify the originality of submitted assessments so as to stem plagiarism.

It should be noted, however, that the splinters of the EMINDA framework presented in Figure 2 is not one that is entirely new to the specialisation of cyber security. The concept of security scanners as illustrated in this framework has been utilised extensively in modern electronic mail platforms to verify the safety of digital media that are propagated by e-mail, before users are able to download and access them. Similarly, the concept of content filters \& classifiers has also been observed as a security feature in some modern web browsers to filter off profanity and obscenity for minors as part of a parental control add-on. However, this propositional cybersecurity framework is one which extent is yet to be widely considered and fully explored within the application domain of TeLEs, because unfortunately, the P2 model proposed by Bronack, et al. (2008) makes no implicit or explicit provisions for the cyber security of participants within virtual learning environments.

Indeed, the concern of quality of service may come to bear when the rubber meets the road in trying to apply the proposed cybersecurity framework. However, drawing on the advancements and prospects of modern system optimisation techniques, with broadband communication capabilities and high-end computing infrastructure would do a great deal to convincingly assuage this concern.

\section{CONCLUSION \& FUTURE RESEARCH}

The revolutionary impact of technology and digitization of teaching and learning in the modern era has come to stay, with exciting prospects for the future of the emerging global information society. At the same time, the realities of global cybersecurity have equally come to stay with rather daunting consequences and debilitating future prospects.

The research presented an overview of the current status of development of IAE and TeLEs, as well as the nature of the realities associated with contemporary concerns of global cybersecurity. These concerns were discovered to include: Academic Dishonesty, Misconduct and Malpractice, Fake News, Steganography \& Malware, and Cyberbullying. The interrogation of these concerns led to an elucida- 
tion of the associated factors and interactions that have hampered the wider development and adoption of IAE and TeLEs for education, teaching and learning in the $21^{\text {st }}$ century. These were properly positioned in reality by drawing on evidences in existing researches, and supported with real-life case studies to explain the implications of the portended realities for the emerging global information society.

The EMINDA cybersecurity framework for TeLEs was presented as a better way forward for lifting the future of IAE and TeLEs out of the quagmire it has been plunged into by the contemporary concerns of global cybersecurity. This framework synthesizes existing security strategies that have been deployed successfully to insure cybersecurity for various other digital and technological application domains.

Future research would now focus on implementing the proposed cybersecurity framework in a prototype TeLE, and evaluating the effectiveness and efficiency of the framework in guaranteeing cybersecurity for a test case sample of participants that would feature in the evaluation.

\section{REFERENCES}

Alexander, B., Becker, S. A., Cummins, M., \& Giesinger, C. H. (2017). Digital literacy in higher education, Part II: An NMC borizon project strategic brief. The New Media Consortium. Retrieved from https://www.learntechlib.org/p/182086/report 182086.pdf

Arnal Wishnowski, L., Yu, C. T., Pear, J., Chand, C., \& Saltel, L. (2018). Effects of computer-aided instruction on the implementation of the MSWO stimulus preference assessment. Behavioral Interventions, 33(1), 56-68. https://doi.org/10.1002/bin.1508

Aydin, G. (2015). The effects of computer-aided concept cartoons and outdoor science activities on light pollution. International Electronic Journal of Elementary Education, 7(2), 142-156. Retrieved from https:// files.eric.ed.gov/fulltext/EJ1057858.pdf

Babiker, M., \& Elmagzoub, A. (2015). For effective use of multimedia in education, teachers must develop their own educational multimedia applications. Turkish Online Journal of Educational Technology-TOJET, 14(4), 6268. Retrieved from https:// files.eric.ed.gov/fulltext/EJ1077625.pdf

Becerra, D. A., Quispe, J. A., Aceituno, R. G., Vargas, G. M., Zamora, F. G., Mango, J. L., .. . Chana, J. W. (2017). Evaluation of a gamified 3D virtual reality system to enhance the understanding of movement in physics. CSEDU, 1, 395-401. https://doi.org/10.5220/0006328003950401

Black, E. W., Greaser, J., \& Dawson, K. (2008). Academic dishonesty in traditional and online classrooms: Does the "media equation" hold true? Journal of Asynchronous Learning Networks, 12(3-4), 23-30. Retrieved from https:// files.eric.ed.gov/fulltext/EJ837484.pdf

Blau, I., \& Eshet-Alkalai, Y. (2017). The ethical dissonance in digital and non-digital learning environments: Does technology promotes cheating among middle school students? Computers in Human Behavior, 73, 629637. https://doi.org/10.1016/i.chb.2017.03.074

Bogdanoski, M., Risteski, A., \& Bogdanoski, M. (2015). Steganography in support of the global terrorism. In M. N. Ogun (Ed.), Terrorist use of cyberspace and cyber terrorism: New challenges and responses (pp. 15-28). IOS Press.

Bower, M., Lee, M. J., \& Dalgarno, B. (2017). Collaborative learning across physical and virtual worlds: Factors supporting and constraining learners in a blended reality environment. British Journal of Educational Technology, 48(2), 407-430. https://doi.org/10.1111/bjet.12435

Bronack, S., Sanders, R., Cheney, A., Riedl, R., Tashner, J., \& Matzen, N. (2008). Presence pedagogy: Teaching and learning in a 3D virtual immersive world. International Journal of Teaching and Learning in Higher Education, 20(1), 59-69. Retrieved October 13, 2018, from https:// files.eric.ed.gov/fulltext/EJ895226.pdf

Burney, M. L. (2018). The history of steganography and the threat posed to the United States and the rest of the international community. Doctoral dissertation: Utica College, NY, USA. 
Casey, K., Casey, M., \& Griffin, K. (2018). Academic integrity in the online environment: Teaching strategies and software that encourage ethical behaviour. Institute for Global Business Research Conference Proceedings, 2(3), 58-66. Nashville, TN, USA.: Institute for Global Business Research.

Castellanos, M., Manson, S., \& Zhou, J. (2017). Hate speech and hate crimes on campus. In J. F. Jackson, L. J. Charleston, \& C. Gilbert (Eds.), Advancing equity and diversity in student affairs: A festschrift in honor of Melvin $C$. Terrell (pp. 113-132). Charlotte, NC.: Information Age Publishing, Inc.

Chen, C. M., \& Wu, C. H. (2015). Effects of different video lecture types on sustained attention, emotion, cognitive load, and learning performance. Computers \& Education, 80, 108-121. https://doi.org/10.1016/j.compedu.2014.08.015

Cheney, A. W., \& Terry, K. P. (2018). Immersive learning environments as complex dynamic systems. International Journal of Teaching \& Learning in Higher Education, 30(2), 277-289. Retrieved from https:// files.eric.ed.gov/fulltext/EJ1185091.pdf

Cingi, C. C. (2013). Computer aided education. Procedia - Social and Behavioral Sciences, 103, 220-229. https://doi.org/10.1016/j.sbspro.2013.10.329

Coglitore, A. (2017). Terrorism spreading by way of the internet. Doctoral dissertation: Utica College, NY, USA.

Cronan, T. P., McHaney, R., Douglas, D. E., \& Mullins, J. K. (2017). Changing the academic integrity climate on campus using a technology-based intervention. Ethics \& Behavior, 27(2), 89-105. https://doi.org/10.1080/10508422.2016.1161514

Cullen, F. T. (2017). Risk, terrorism, and the Internet. In D. Clarke (Ed.), Technology and terrorism (pp. 165-176). Routledge.

Davis, M. R. (2012, April 03). Students create fake online profiles to bully peers. Education Week. Retrieved October 10, 2018, from https://www.edweek.org/ew/articles/2012/04/04/27facebook.h31.html

de Jager, T. (2017). Perceived advantages of 3D lessons in constructive learning for South African student teachers encountering learning barriers. International Journal of Inclusive Education, 21(1), 90-102. https://doi.org/10.1080/13603116.2016.1184329

De León, L. (2018). Learning child development through immersion in ill-structured problems using a virtual environment. In D. Beck, C. Allison, L. Morgado, J. Pirker, A. Peña-Rios, T. Ogle, . . C. Gütl (Eds.), 4th International Conference on Immersive Learning. Communications in Computer and Information Science, 840, pp. 148-159. Missoula, MT, USA: Springer, Cham. https://doi.org/10.1007/978-3-319-93596-6 10

Doumanis, I., Economou, D., Sim, G. R., \& Porter, S. (2018). The impact of multimodal collaborative virtual environments on learning: A gamified online debate. Computers \& Education, 130, 121-138. https://doi.org/10.1016/j.compedu.2018.09.017

Eaton, D. R. (2016). Steganalysis and the perpetuation of crime using steganography. Doctoral dissertation: Utica College, NY, USA.

Ferdig, R. E., Gandolfi, E., \& Immel, Z. (2018). Educational opportunities for immersive virtual reality. In J. Voogt, G. Knezek, R. Christensen, \& K. W. Lai (Eds.), Second handbook of information technology in primary and secondary education (pp. 1-12). Springer, Cham.

Gautam, A., Williams, D., Terry, K., Robinson, K., \& Newbill, P. (2018). Mirror worlds: examining the affordances of a next generation immersive learning environment. TechTrends, 62(1), 119-125. https://doi.org/10.1007/s11528-017-0233-x

Greenwald, S., Kulik, A., Kunert, A., Beck, S., Frohlich, B., Cobb, S., . . Maes, P. (2017). Technology and applications for collaborative learning in virtual reality. In B. Smith, M. Borge, E. Mercier, \& K. Lim (Eds.), 12th International Conference on Computer Supported Collaborative Learning (CSCL) (pp. 719-726). Pennsylvania, USA: International Society of the Learning Sciences, Philadelphia, PA, USA. Retrieved October 10, 2018, from http://eprints.uwe.ac.uk/32215/1/115.pdf

Jones, P. R. (2016). The structure and pedagogical style of the virtual developmental education classroom: Benefit or barrier to the developmental learning process? International Journal of Language and Literature, 4(1), 4348. 
Kumar, D., Kumar, N., \& Kumar, A. (2014). Computer viruses and challenges for anti-virus industry. International Journal of Engineering and Computer Science, 3(2), 3869-3872.

Kwon, S. R., Hernández, M., Blanchette, D. R., Lam, M. T., Gratton, D. G., \& Aquilino, S. A. (2015). Effect of computer-assisted learning on students' dental anatomy waxing performance. Journal of Dental Education, 79(9), 1093-1100. Retrieved from http://www.jdentaled.org/content/jde/79/9/1093.full.pdf

Lee-Post, A., \& Hapke, H. (2017). Online learning integrity approaches: Current practices and future solutions. Online Learning, 21(1), 135-145. https://doi.org/10.24059/olj.v21i1.843

Leow, F. T., \& Neo, M. (2014). Interactive multimedia learning: Innovating classroom education in a Malaysian university. Turkish Online Journal of Educational Technology-TOJET, 2, 99-110. Retrieved from https:// files.eric.ed.gov/fulltext/EJ1022913.pdf

Liu, D., Bhagat, K. K., Gao, Y., Chang, T. W., \& Huang, R. (2017). The potentials and trends of virtual reality in education: A bibliometric analysis on top research studies in the last two decades. In D. Liu, C. Dede, R. Huang, \& J. Richards (Eds.), Virtual, augmented, and mixed realities in education (pp. 105-130). Springer, Singapore. https://doi.org/10.1007/978-981-10-5490-7 7

Liu, R., Liu, C., \& Ren, Y. (2018). A virtual reality application for primary school mathematics class. 2018 International Symposium on Educational Technology (ISET) (pp. 138-141). Osaka, Japan: IEEE. https://doi.org/10.1109/ISET.2018.00038

Lowry, P. B., Zhang, J., Wang, C., \& Siponen, M. (2016). Why do adults engage in cyberbullying on social media? An integration of online disinhibition and deindividuation effects with the social structure and social learning model. Information Systems Research, 27(4), 962-986. https://doi.org/10.1287/isre.2016.0671

McGrew, S., Ortega, T., Breakstone, J., \& Wineburg, S. (2017). The challenge that's bigger than fake news: Civic reasoning in a social media environment. American Educator, 41(3), 4-9. Retrieved from https:/ / files.eric.ed.gov/fulltext/EJ1156387.pdf

Minor, M. A., Smith, G. S., \& Brashen, H. (2013). Cyberbullying in higher education. Journal of Educational Research and Practice, 3(1), 15-29. Retrieved from https://scholarworks.waldenu.edu/cgi/viewcontent.cgi?article $=1043 \&$ context $=$ jerap

Mo, D., Huang, W., Shi, Y., Zhang, L., Boswell, M., \& Rozelle, S. (2015). Computer technology in education: Evidence from a pooled study of computer assisted learning programs among rural students in China. China Economic Review, 36, 131-145. https://doi.org/10.1016/i.chieco.2015.09.001

Mortara, M., \& Catalano, C. E. (2018). 3D virtual environments as effective learning contexts for cultural heritage. Italian Journal of Educational Technology, 26(2), 5-21. Retrieved from https://www.learntechlib.org/p/195252/article 195252.pdf

Ng'ambi, D., Brown, C., Bozalek, V., Gachago, D., \& Wood, D. (2016). Technology enhanced teaching and learning in South African higher education - A rearview of a 20 year journey. British Journal of Educational Technology, 47(5), 843-858. https://doi.org/10.1111/bjet.12485

Nicolaides, A. (2018). The pursuit of ethical practice in distance higher education assessment in a business leadership school. Global Journal of Economics and Business Administration, 3. https://doi.org/10.28933/gjeba2018-01-1802

Olmos, E., Cavalcanti, J. F., Soler, J. L., Contero, M., \& Alcañiz, M. (2018). Mobile virtual reality: A promising technology to change the way we learn and teach. In S. Yu, M. Ally, \& A. Tsinakos (Eds.) Mobile and ubiquitous learning (pp. 95-106). https://doi.org/10.1007/978-981-10-6144-8 6

Ozofor, N. M. (2015). Effect of two modes of computer aided instruction on students'achievement and interest in statistics and probability. International Journal of Education and Research, 3(1), 89-102. Retrieved October 10, 2018, from http://eprints.gouni.edu.ng/155/1/effect-of-two-modes-of-computer-aided-instructionon $\% 20$ students $\%$ e $\% 80 \% 99$-achievement-and-interest-in-statistics-and-probability.pdf

Román-Ibáñez, V., Pujol-López, F. A., Mora-Mora, H., Pertegal-Felices, M. L., \& Jimeno-Morenilla, A. (2018). A low-cost immersive virtual reality system for teaching robotic manipulators programming. Sustainability, 10(4), 1102. https://doi.org/10.3390/su10041102 
Rout, H., \& Mishra, B. K. (2014). Pros and cons of cryptography, steganography and perturbation techniques. IOSR Journal of Electronics and Communication Engineering, 76-81. Retrieved from https://www.researchgate.net/profile/Brojo Mishra2/publication/286092142 Pros and Cons of Crypt ography Steganography and Perturbation techniques/links/56660a3208ae418a786f3afb.pdf

Sapouna, M., Enz, S., Samaras, M., \& Wolke, D. (2015). Learning how to cope with cyberbullying in the virtual world: Lessons from FearNot! In T. Völlink, F. Dehue, \& C. M. Guckin (Eds.), Cyberbullying: from theory to intervention (pp. 79-92). Routledge. https://doi.org/10.4324/9781315680354-5

Sarac, H. S. (2014). Benefits and challenges of using second life in English teaching: Experts' opinions. Procedia - Social and Behavioral Sciences, 158, 326 - 330. https://doi.org/10.1016/i.sbspro.2014.12.095

Sarwar, B., Zulfiqar, S., Aziz, S., \& Ejaz Chandia, K. (2019). Usage of social media tools for collaborative learning: The effect on learning success with the moderating role of cyberbullying. Journal of Educational Computing Research, 57(1), 246-279. https://doi.org/10.1177/0735633117748415

Scamell, M., \& Hanley, T. (2017). Innovation in preregistration midwifery education: Web based interactive storytelling learning. Midwifery, 50, 93-98. https://doi.org/10.1016/j.midw.2017.03.016

Schott, C., \& Marshall, S. (2018). Virtual reality and situated experiential education: A conceptualization and exploratory trial. Journal of Computer Assisted Learning 34(6), 843-852. https://doi.org/10.1111/jcal.12293

Smith, J. A., \& Yoon, J. (2012). Cyberbullying presence, extent, \& forms in a Midwestern post-secondary institution. 2012 Proceedings of the Information Systems Educators Conference. 2167, (pp. 1435). New Orleans, Louisiana, USA: EDSIG (Education Special Interest Group of the AITP). Retrieved October 10, 2018, from http://citeseerx.ist.psu.edu/viewdoc/download?doi=10.1.1.296.8466\&rep=rep1\&type=pdf

Storms, J. E. (2016). An evaluation of the history, demand, and current methods for digital steganography. Doctoral dissertation: Utica College, NY, USA.

Symantec. (2017, June). Big Numbers. Internet Security Threat Report, 22(1). Retrieved March 02, 2018, from https: $/ /$ resource.elq.symantec.com $/ \mathrm{LP}=3980$ ? cid $=70138000001 \mathrm{BjppAAC \& mc}=202671 \& \mathrm{ot}={ }_{\mathrm{wp} \& \mathrm{tt}}=\mathrm{sw} \&$ inid=symc threat-report regular to leadgen form LP-3980 ISTR22-report-main

Thomas, M., \& Schneider, C. (2018). Language teaching in 3D virtual worlds with machinima: Reflecting on an online machinima teacher training course. International Journal of Computer-Assisted Language Learning and Teacbing (IJCALLT), 8(2), 20-38. https://doi.org/10.4018/IJCALLT.2018040102

Torres, F. C., \& Vivas, G. M. (2016). Cyberbullying and education: A review of emergent issues in Latin America research. In R. Navarro, S. Yubero, \& E. Larrañaga (Eds.), Cyberbullying across the globe (pp. 131-147). Springer, Cham. https://doi.org/10.1007/978-3-319-25552-1_7

Trelease, R. B. (2016). From chalkboard, slides, and paper to e-learning: How computing technologies have transformed anatomical sciences education. Anatomical Sciences Education, 9(6), 583-602. https://doi.org/10.1002/ase.1620

Tsai, N. W. (2016). Assessment of students' learning behavior and academic misconduct in a student-pulled online learning and student-governed testing environment: A case study. Journal of Education for Business, 91(7), 387-392. https://doi.org/10.1080/08832323.2016.1238808

Uzunboylu, H., \& Tugun, V. (2016). Validity and reliability of tablet supported education attitude and usability scale. Journal of Universal Computer Science, 22(1), 82-93. Retrieved October 10, 2018, from https://pdfs.semanticscholar.org/15c8/0933ac54775bd93cef472ab9847e8c7ebe96.pdf

Wang, Y. F., Petrina, S., \& Feng, F. (2017). VILLAGE - Virtual Immersive Language Learning and Gaming Environment: Immersion and presence. British Journal of Educational Technology, 48(2), 431-450. https://doi.org/10.1111/bjet.12388 


\section{BIOGRAPHIES}

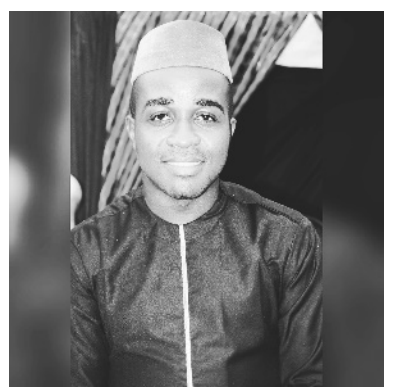

Emmanuel C. OGU holds a BSc. Degree in Computer Science (Technology), a MSc. Degree in Computer Science (Networking and Telecommunications), and a $\mathrm{PhD}$ in Computer Science with a research focus in Cyber \& Network Security, all from Babcock University, Nigeria. His research interests cover a broad range of multidisciplinary topics related to contemporary issues and discourses in Cybersecurity, Security Policy \& Legislation, Business Information Technologies, and Sustainable Development. He has authored and co-authored over a dozen peer-reviewed and referred research articles in the areas of his research interests, which have been published by reputable international journals and indexed in global repositories.

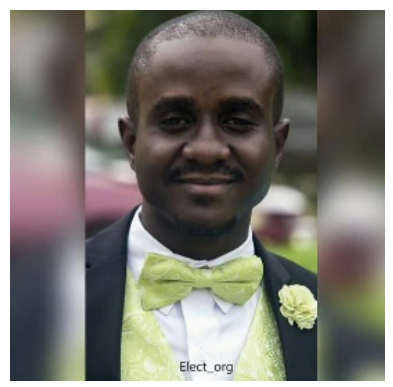

Chiemela OGU is an Independent Researcher affiliated with EMINDA Konsults, Yaba, Lagos, Nigeria. His research areas include: Computer Security, Information Security, Network Technology, and Cloud Computing. 